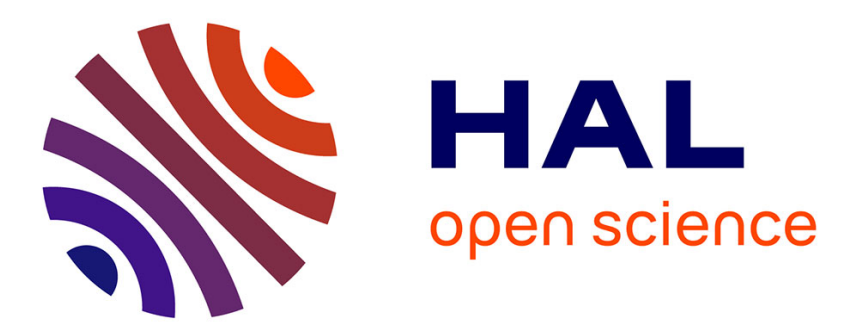

\title{
Monitoring of pavement deflections using geophones
}

Ngoc Son Duong, Juliette Blanc, Pierre Hornych, Fabien Menant, Yann

Lefeuvre, Benoit Bouveret

\section{To cite this version:}

Ngoc Son Duong, Juliette Blanc, Pierre Hornych, Fabien Menant, Yann Lefeuvre, et al.. Monitoring of pavement deflections using geophones. International Journal of Pavement Engineering, 2018, 21 (9), 12p. 10.1080/10298436.2018.1520994 . hal-01923122

\section{HAL Id: hal-01923122 \\ https://hal.science/hal-01923122}

Submitted on 7 Jun 2021

HAL is a multi-disciplinary open access archive for the deposit and dissemination of scientific research documents, whether they are published or not. The documents may come from teaching and research institutions in France or abroad, or from public or private research centers.
L'archive ouverte pluridisciplinaire $\mathbf{H A L}$, est destinée au dépôt et à la diffusion de documents scientifiques de niveau recherche, publiés ou non, émanant des établissements d'enseignement et de recherche français ou étrangers, des laboratoires publics ou privés. 


\section{Monitoring of pavement deflections using geophones}

Ngoc Son Duong ${ }^{1}$, Juliette Blanc ${ }^{1 *}$, Pierre Hornych ${ }^{1}$, Fabien Menant ${ }^{1}$, Yann Lefeuvre ${ }^{2}$ and Benoit Bouveret ${ }^{2}$

1 Materials and Structures (MAST) Department, IFSTTAR, Allée des Ponts et Chaussées, CS4, 44344 Bouguenais, CedexFrance; juliette.blanc@ifsttar.fr

2 Infrastructures Engineering Department, Campus for Sciences and Techniques, Colas, 4 rue Jean Mermoz, CS 30504, 78772 Magny-les-Hameaux Cedex, France

Correspondence: juliette.blanc@ifsttar.fr; Tel.: +33 240845776

International Journal of Pavement Engineering, Taylor \& Francis Group, 21, 9 (2018) https://doi.org/10.1080/10298436.2018.1520994 


\title{
Monitoring of pavement deflections using geophones
}

\begin{abstract}
: the paper presents tests performed on an instrumented motorway section, to monitor traffic and pavement deflections using geophones. Geophones are sensors used to measure displacement velocities, and by integrating their signal, it is possible to monitor vertical displacements in the pavement structure. In this study, 4 geophones have been installed in the base layer of the pavement, during construction, and their measurements have been recorded under real traffic, during a period of approximately 18 months, using a remote control data acquisition system, transferring the data to a server.

Different methods of treatment of the geophone measurements have been proposed : the first application concerns the detection of different heavy vehicle silhouettes, by analyzing the number of peaks of the displacement signals; the second application concerns the measurement of vehicle speeds, by determining the time difference between the measurements of two geophones, placed longitudinally in the base layer, under the wheelpath. The third application concerns the measurement of pavement deflections. To measure accurately the deflection, a procedure has been developed, to correct the geophone response, which is attenuated in the low frequency range (below $4.5 \mathrm{~Hz}$ ). This procedure has been validated by measurements under controlled loading conditions, on the IFSTTAR full scale accelerated pavement testing facility, and then applied to in situ measurements. In conclusion, the study shows that geophones, which present the advantage of being relatively inexpensive and robust sensors, offer interesting possibilities for pavement monitoring.
\end{abstract}

Keywords: Pavement monitoring; remote monitoring; geophone; data acquisition; deflection

\section{Introduction}

This study presents the instrumentation of an experimental pavement section, located on a French motorway, which is subjected to very heavy traffic (around 4,500 trucks/day). For safety reasons, closing the slow lane to make measurements with a 
reference vehicle seemed difficult on this site, and for this reason, it was decided to test the installation of an instrumentation and data acquisition system with remote control and remote data transfer. Such a monitoring system presents several advantages :

- Remote control of instrumentation is particularly appropriate in the context of a heavy traffic motorway, due to difficulties of access to the site.

- Remote data transfer allows to monitor continuously pavement response, under normal traffic. (The transducer signals under the passage of all heavy vehicles can be recorded, for example). It is thus possible to study in detail the variations of the pavement response with traffic and climatic variations (temperature, moisture conditions...).

Conversely, difficulty associated with such monitoring under real traffic lies in the absence of precise information on the characteristics of the traffic loads (vehicle speeds, transverse wandering, axle loads).

The experimental section is located on the slow lane of the motorway, which was reconstructed in 2013. The pavement section was instrumented during reconstruction, from 16 to 19 September 2013. The instrumentation installed included classical sensors, generally used at IFSTTAR for monitoring of pavement sections : strain gages for measuring the horizontal strains at the bottom of the asphalt layers, and temperature probes. In addition, it was decided to test the possibility of using geophones, as additional instrumentation, for the measurement of pavement deflections. Geophones are relatively simple and robust sensors which use the principle of a spring-mounted magnetic mass moving within a wire coil. They are generally used for applications such as detection of ground movements (for seismic applications) or vibrations. They deliver an electrical signal which is proportional to the vertical 
displacement velocity (Oome et al., 2009). They are also used in the Falling Weight Deflectometer (FWD), for measurement of pavement deflections. By integrating their measurements, it is possible to determine a displacement (Katicha et al., 2013 and Al Hakim et al., 2007). Thus, by placing geophones vertically, in the upper pavement layers, it seemed possible to measure the pavement deflection, under the passage of heavy vehicles. This kind of study was already made at the Minnesota Department of Transportation's MnROAD pavement test-track facility. One of the FHWA (Federal Highway Administration) studies used geophones to evaluate the accuracy and precision of Traffic Speed Deflection Devices such as TSD and RWD . The geophones were used only for a short term (and signals were recorded only under TSD passages) but this study has shown that it was feasible to measure the deflection using geophones (FHWA, 2016).

Therefore, in this project, it was decided to install several geophones at different positions in the pavement structure, and to try to use their measurements to analyse the passing traffic, and the pavement deflections.

Geophones have not been frequently used for internal instrumentation of pavements, but the authors believe that they can represent a very interesting alternative to other systems, like deflectometers (displacement sensors, which measure the displacement between the pavement surface, and a fixed point, located at a depth of several meters), because they are much cheaper, and much simpler to install in the pavement (no boring to several meters depth is required). Installing the geophones in the pavement structure also allows to make continuous measurements, and thus to monitor accurately the daily and seasonal variations of the deflection, which is not possible with an FWD, which can make only only a few series of measurements per year. 


\section{Pavement structure and instrumentation}

\subsection{Pavement structure}

The experimental section consists of six different layers (Table 1). The three upper layers were rebuilt during the rehabilitation, in 2013. They consist of a wearing course (very thin asphalt concrete, VTAC), a binder course (high modulus bituminous concrete, HMBC) and a base course (high modulus mix HMAC). The lower layers, which include a cracked GSB layer (Gravel stabilised with bitumen) a cement treated sand layer and the subgrade are older layers (more than 20 years old), which have been left in place.

Table 1. Structure of the experimental section

\begin{tabular}{ccc}
\hline Materials & $\begin{array}{c}\text { Elastic modulus } \\
(\mathbf{M P a}) \text { at } \mathbf{1 5}^{\circ} \mathbf{C}, \mathbf{1 0 H z}\end{array}$ & $\begin{array}{c}\text { Thickness } \\
(\mathbf{c m})\end{array}$ \\
\hline Very thin asphalt concrete (VTAC) & 3000 & 2.5 \\
High modulus bituminous concrete & 11000 & 6 \\
(HMBC) & 14000 & 7 \\
High modulus asphalt concrete (HMAC) & 5000 & 8 \\
Gravel stabilized with bitumen (GSB) & 14000 & 30 \\
Cement treated sand & 150 & 50 \\
Subgrade &
\end{tabular}

\subsection{Pavement instrumentation}

The experimental section is located on a motorway, in France. The slow lane has been instrumented using temperature probes, strain gages and geophones. The instrumentation layout of the studied section is presented in Figure 1. The instrumentation includes:

- 8 temperature probes PT100 installed at the bottom of each bituminous layer (2 probes per layer).

- 4 geophones placed at the bottom of the HMAC layer. The geophones measure the vertical velocity of displacement of the pavement layers. The objective was 
to try to use the geophones to measure the vertical displacements in the

pavement structure, by integrating the displacement velocity measurements.

- 8 strain gages, placed in the longitudinal and transversal direction, at the bottom of the HMBC layer (4 gages), and at the bottom of the HMAC layer (4 gages).

The geophones used are Geospace GS-11D, with a closing resistance of $47 \mathrm{k} \Omega$. This kind of sensors has also been used by (Lenglet et al., 2017) on another instrumented site. In order to evaluate the lateral wander of traffic, three geophones have been placed at different lateral positions ( $15 \mathrm{~cm}$ apart), at the bottom of the HMAC layer. In order to evaluate the speed of vehicles, two geophones have also been placed at the bottom of the HMAC layer, at a distance of 1 meter in the longitudinal direction.

The work presented in this paper concerns only the analysis of the geophone and temperature measurements. The results of the monitoring with the strain gages are detailed in (Duong et al., 2017 and Duong et al., 2018) and will not be presented here.

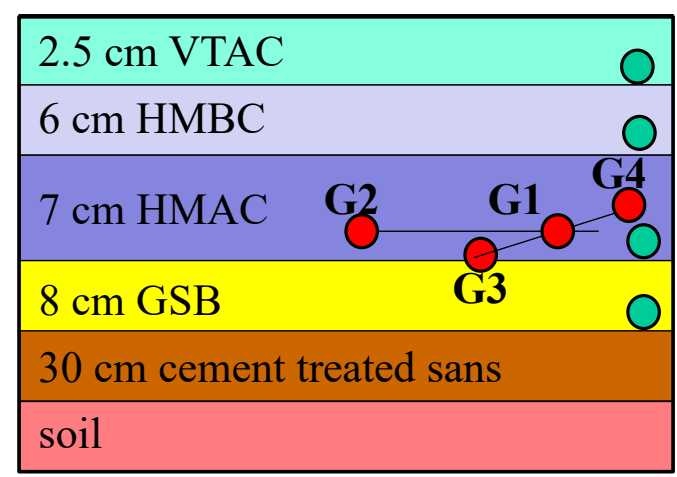

Temperature probe

Geophone

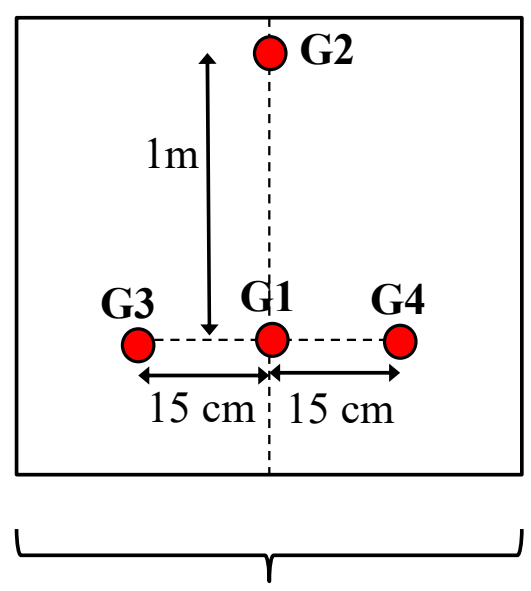

Wheel path of the slow lane

Figure 1. Motorway instrumentation layout (temperature probes and geophones).

\subsection{Description of the remote monitoring system}


The sensors are connected to a remote data acquisition system, called PEGASE Platform, developed at IFSTTAR. The PEGASE Platform consists of a "mother board", which integrates a computation processor (Analog Device Blackfin BF537), data storage, a Wi-Fi communication module and a small and low-power GPS receiver for localization and time synchronization. It also comprises a set of pluggable "daughter boards" including conditioners and analog to digital converters for the different types of transducers (Le Cam et al., 2008) (Figure 2).

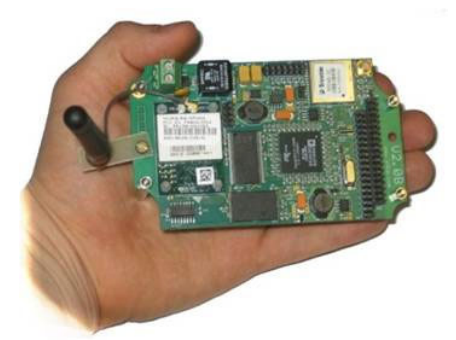

Figure 2. Wireless data acquisition system PEGASE developed at IFSTTAR

The PEGASE system is very compact, modular, and consumes little energy. It has been used for various applications like bridge inspection, cable monitoring or pavement monitoring (Duong et al., 2016, Blanc et al., 2017 and Sohm et al., 2012).

On the site, the PEGASE boards have been installed in a weatherproof cabinet, installed behind the safety barrier (Figure 3).

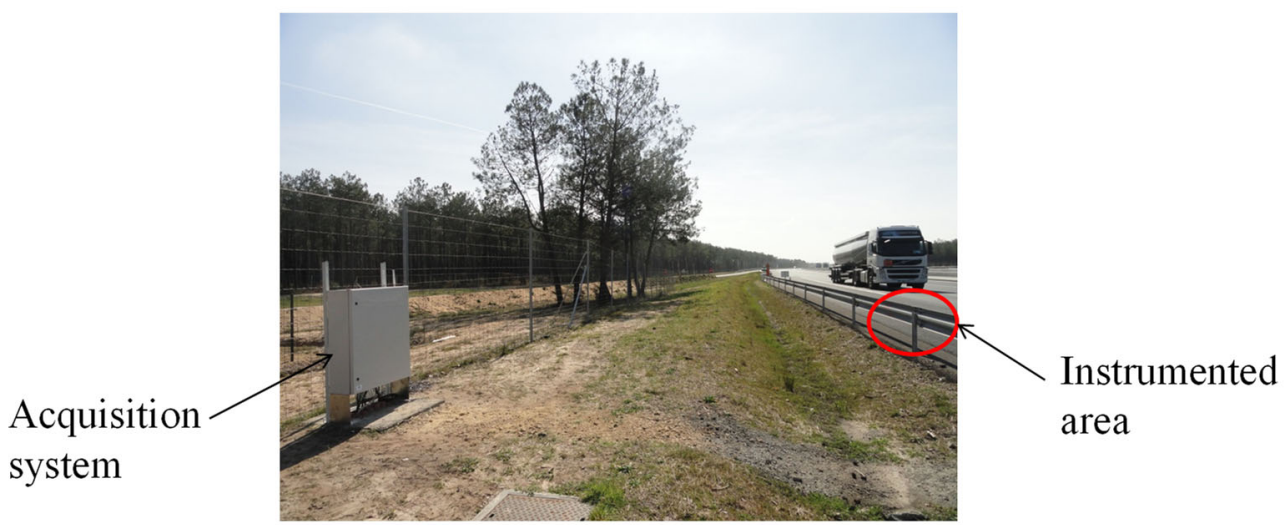

Figure 3. View of the acquisition system and instrumented area 
All the recorded measurements are transferred continuously via 3G network (within a few hours maximum) to a remote server, and stored in a database, for further analysis (Figure 4). Measurements from the instrumented motorway section have been recorded and analyzed since March 2014 for the temperature probes and since May 2015 for the geophones.

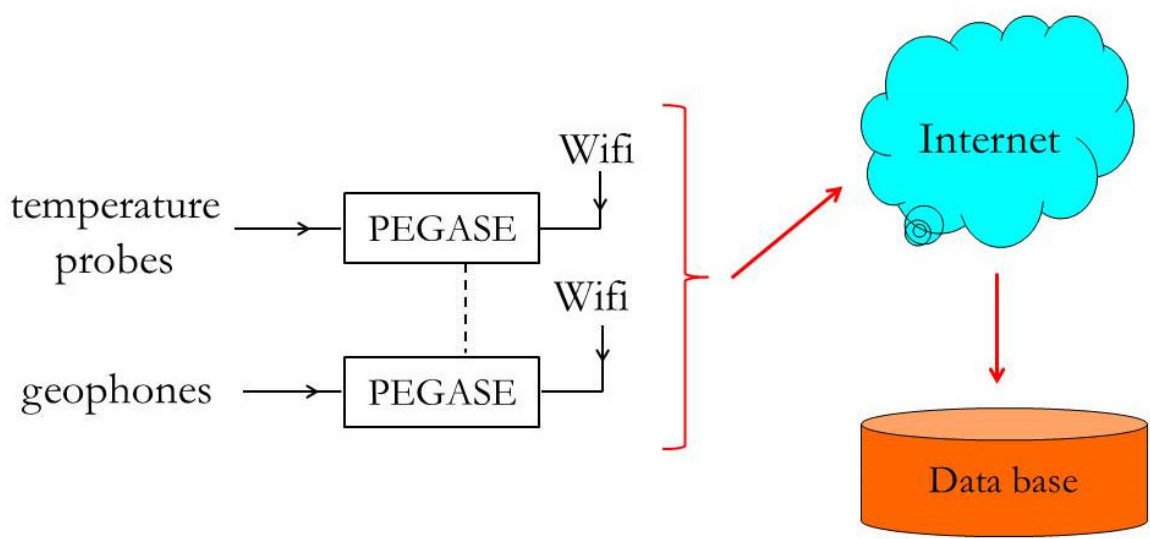

Figure 4. Layout of data acquisition and transmission system

\section{Evaluation of intrinsic characteristics of the geophone by laboratory test}

Before the installation of the pavement monitoring system, laboratory tests were carried out in order to characterize the response of the geophone, under controlled displacement levels, close to the real site conditions (frequency, amplitude). The objective was to determine the frequency response of the geophone, and its sensitivity.

The tests were performed on a vibrating table, with a closed-loop hydraulic loading system, which can apply controlled displacement load signals, with a maximum displacement amplitude of $\pm 50 \mathrm{~mm}$. For the tests, a geophone identical to those used on the site (type Geospace GS-11D) was placed on the vibrating table. The measurements of the geophone were compared with measurements made with a laser displacement sensor (keyence, model LC2100, range $+/-8 \mathrm{~mm}$, accuracy about $5 \mu \mathrm{m}$ ), used to measure the vertical displacement of the table. The laser sensor was used as reference, to evaluate the response of the geophone. The layout of the test is presented in figure 5. 


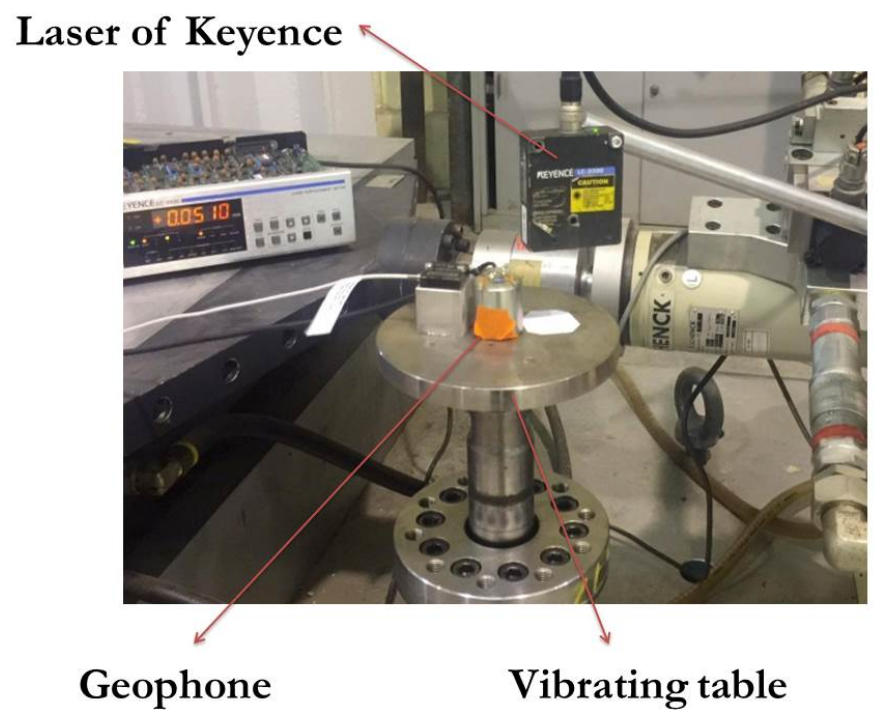

Figure 5. Laboratory test on vibrating table

To evaluate the response of the geophone, the vibrating table was submitted to sinusoidal controlled displacement loadings. Three different displacement levels were applied $(0.25 \mathrm{~mm}, 0.5 \mathrm{~mm}$ and $1 \mathrm{~mm})$, and for each displacement level, a range of frequencies from $1 \mathrm{~Hz}$ to $20 \mathrm{~Hz}$, which correspond to common loading frequencies generated by heavy trucks loads. For instance, for a typical truck speed of $70 \mathrm{~km} / \mathrm{h}$ (approximately $20 \mathrm{~m} / \mathrm{s}$ ), a signal frequency of $20 \mathrm{~Hz}$ corresponds to a signal duration of $0.05 \mathrm{~s}$, and thus a travel distance of $1 \mathrm{~m}$, which is close to the spacing between trailer tridem axles (typically, the spacing is about $1.3 \mathrm{~m}$ ). Similarly, a frequency of $1 \mathrm{~Hz}$ corresponds to a travel distance of $20 \mathrm{~m}$, close to the total length of the truck ( typically $16.5 \mathrm{~m}$ for a European semi-trailer).

For each displacement level, figure 6 presents the ratio between the displacement amplitude measured by the geophone (after integration of the geophone signal) and the reference displacement given by the Keyence laser sensor, as a function of loading frequency. 


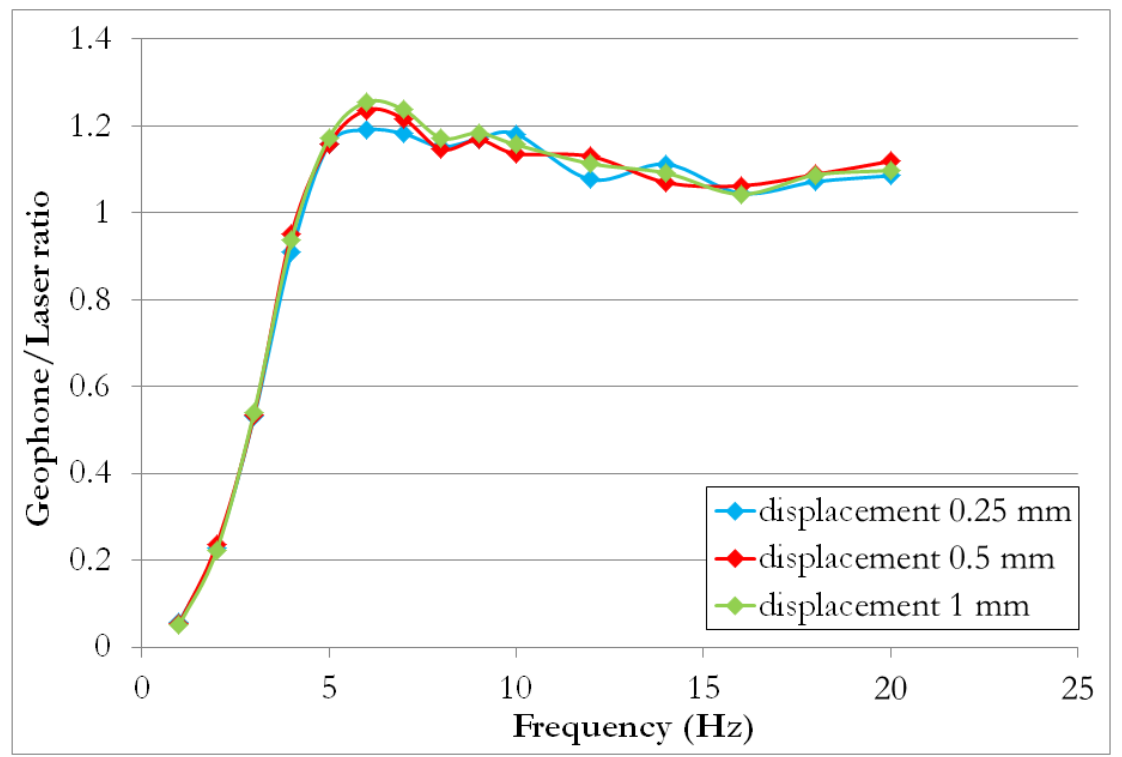

Figure 6. Amplitude ratios between the displacement levels measured by the geophone and the Keyence laser sensor, for three load levels

The results show that the obtained curves have a very similar shape. A nonlinear response of the geophone, leading to a significant attenuation of the measured displacement amplitude is observed in the frequency range $[1-4.5 \mathrm{~Hz}]$. Above $4.5 \mathrm{~Hz}$, the ratio between the displacement amplitude measured by the geophone and the reference value given by the laser sensor tends towards a constant value of about 1.1. It can be noted that the response of the geophone is independent of the amplitude of the displacement, and that the transfer function obtained experimentally is very similar to the transfer function provided by the manufacturer. These results indicate that for low frequencies (approximately below $4.5 \mathrm{~Hz}$ ), a specific treatment of the geophone signal will be needed, to compensate the signal attenuation.

\section{Results of the in situ geophone measurements}

\subsection{Examples of geophone measurements}


On the experimental pavement section, geophone measurements are recorded only when the level of displacement velocity exceeds a triggering threshold. Thus, only the signals corresponding to heavy goods vehicles are recorded and not those corresponding to passenger cars. Examples of signals of a geophone (raw and integrated signal) are presented on figure 7.

raw signal of geophone
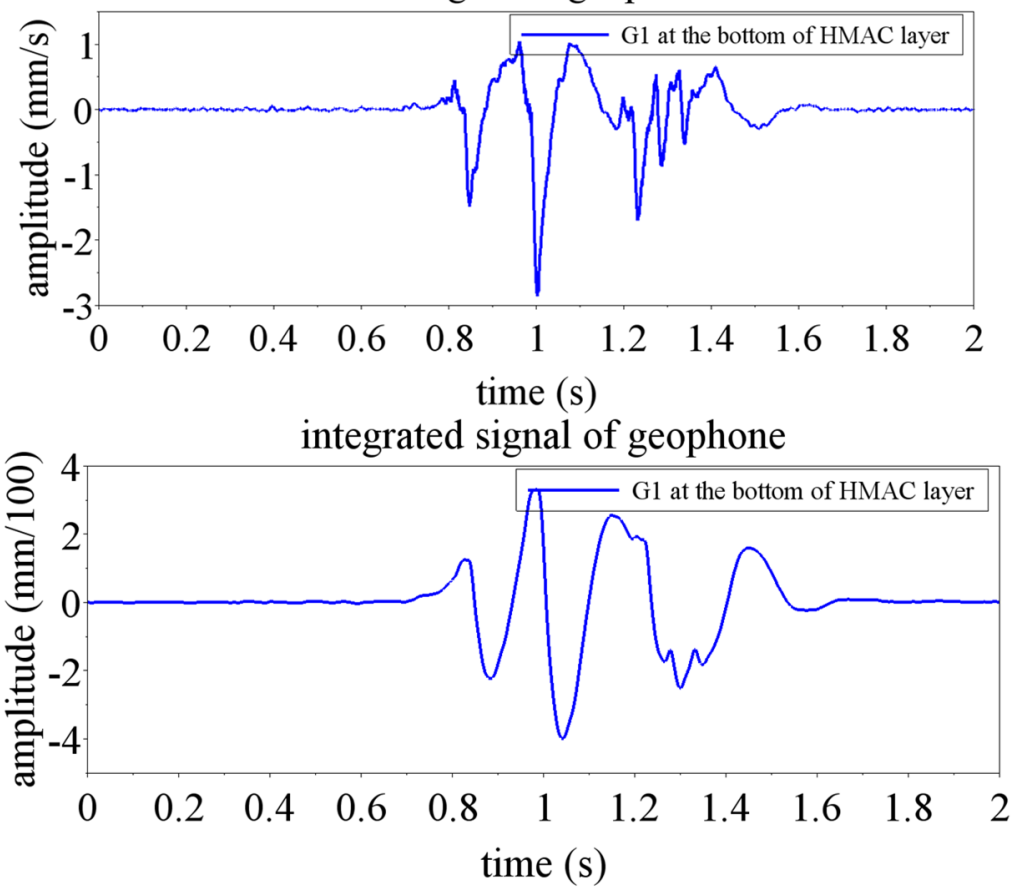

Figure 7. Examples of raw and integrated signal of a geophone under the passage of a 5axle heavy goods vehicle

The analysis of the recorded geophone signals has suggested that the measurements could be used for two types of applications :

- the characterisation of the heavy vehicle traffic (identification of vehicle silhouettes, estimation of vehicle speeds)

- the monitoring of pavement deflections, and their analysis, taking into account vehicle speeds, and pavement temperatures. 


\subsection{Characterization of heavy vehicle silhouettes}

As discussed in $\S 4.1$, the integrated geophone signals present a shape, which is, at least qualitatively, similar to the deflection produced by the passage of the heavy goods vehicle on the pavement. Each peak of the signal corresponds clearly to one axle of the vehicle. Therefore, by counting the negative displacement peaks (downward displacements), it is possible to identify the truck silhouettes.

To determine automatically the truck silhouettes, a procedure based on the analysis of the derivative of the displacement signal has been developped, and implemented in the Scilab data analysis software. A peak, or extremum (positive or negative) of the geophone signal is detected by the change of sign of the derivative of the signal. In order to eliminate peaks due to the noise of the signal, the derivative is calculated over an interval of 20 measurement points.

$$
f^{\prime}\left(A_{1}-A_{20}\right)=\frac{f\left(x_{20}\right)-f\left(x_{1}\right)}{x_{20}-x_{1}}
$$

Where $\mathrm{Ai}$ is a point of coordinate $\mathrm{Ai}(\mathrm{xi}, \mathrm{f}(\mathrm{xi}))$.

The principle of the peak identification is the following :

- A positive peak is detected when the sign of the derivative changes from positive to negative and the displacement value is positive.

- A negative peak is detected when the sign of the derivative changes from negative to positive and the displacement value is negative.

Figure 8 presents an example of different silhouettes of heavy trucks identified with the procedure developed with Scilab: a 2-axle truck, a 3-axle truck, a 4-axle truck, a 5-axle truck and a 5-axle semi-trailer truck. 
Table 2 presents the selection criteria used for the automatic identification of the different truck silhouettes (number of positive and negative peaks). On figure 8 , positive peaks are identified with red circles and negative peaks are identified with blue circles. The identification process is performed automatically with the Scilab program.

Table 2. Criteria of identification of different vehicle types in function of the number of positive and negative peaks.

\begin{tabular}{cc}
\hline Vehicle type & Number of positive peaks / negative peaks \\
\hline 2-axles truck & $3 / 2$ or $4 / 2$ \\
3-axles truck & $3 / 3,4 / 3,5 / 3$ or $6 / 3$ \\
4 -axles truck & $4 / 4,5 / 4$ or $6 / 4$ \\
& $5 / 5$ (time of $2^{\text {nd }}$ positive peak $<2^{\text {nd }}$ negative peak \\
5 -axles truck & and time of $3^{\text {rd }}$ positive peak $<3^{\text {rd }}$ negative peak) \\
5-axles semi-trailer & $3 / 5,4 / 5,5 / 5,6 / 5$ or $7 / 5$ \\
truck &
\end{tabular}
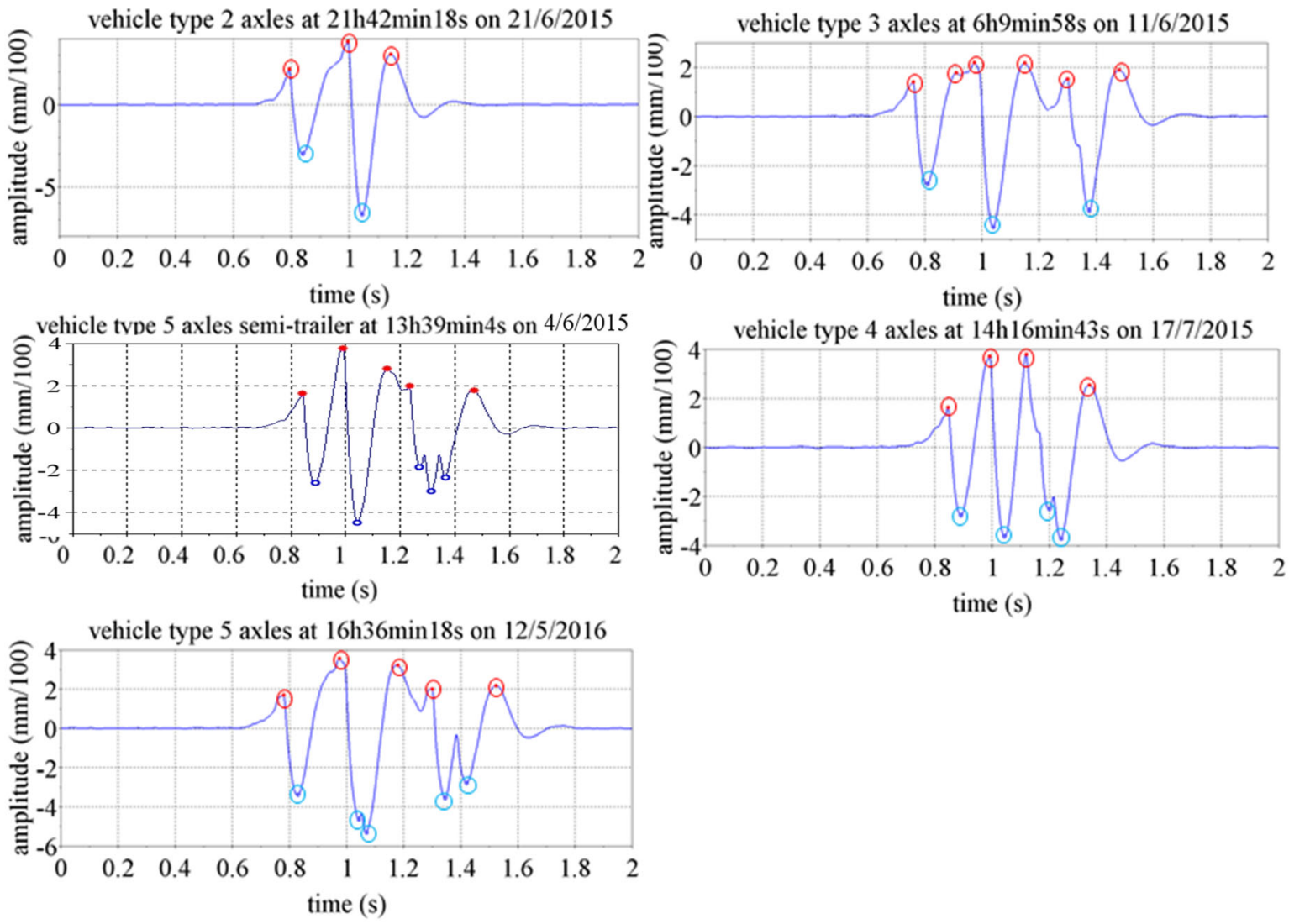

Figure 8. Examples of identification of different heavy vehicle silhouettes using the geophone signals 
Based on the identification procedure described above, the number of different truck types passing on the slow lane of the motorway section during the monitoring period has been calculated and is presented in figure 9 . The results indicate that :

- The number of heavy vehicles increases during summer - the decrease of the number of recorded vehicles at the end of the monitoring period (December 2015 to May 2016) is due to interruptions of the data acquisition system.

- The majority of heavy goods vehicles on this motorway (about $80 \%$ ) are 5-axle semi-trailers, which have a large capacity for long-distance transport. The distribution of the different types of heavy vehicles remains relatively constant during the monitoring period.

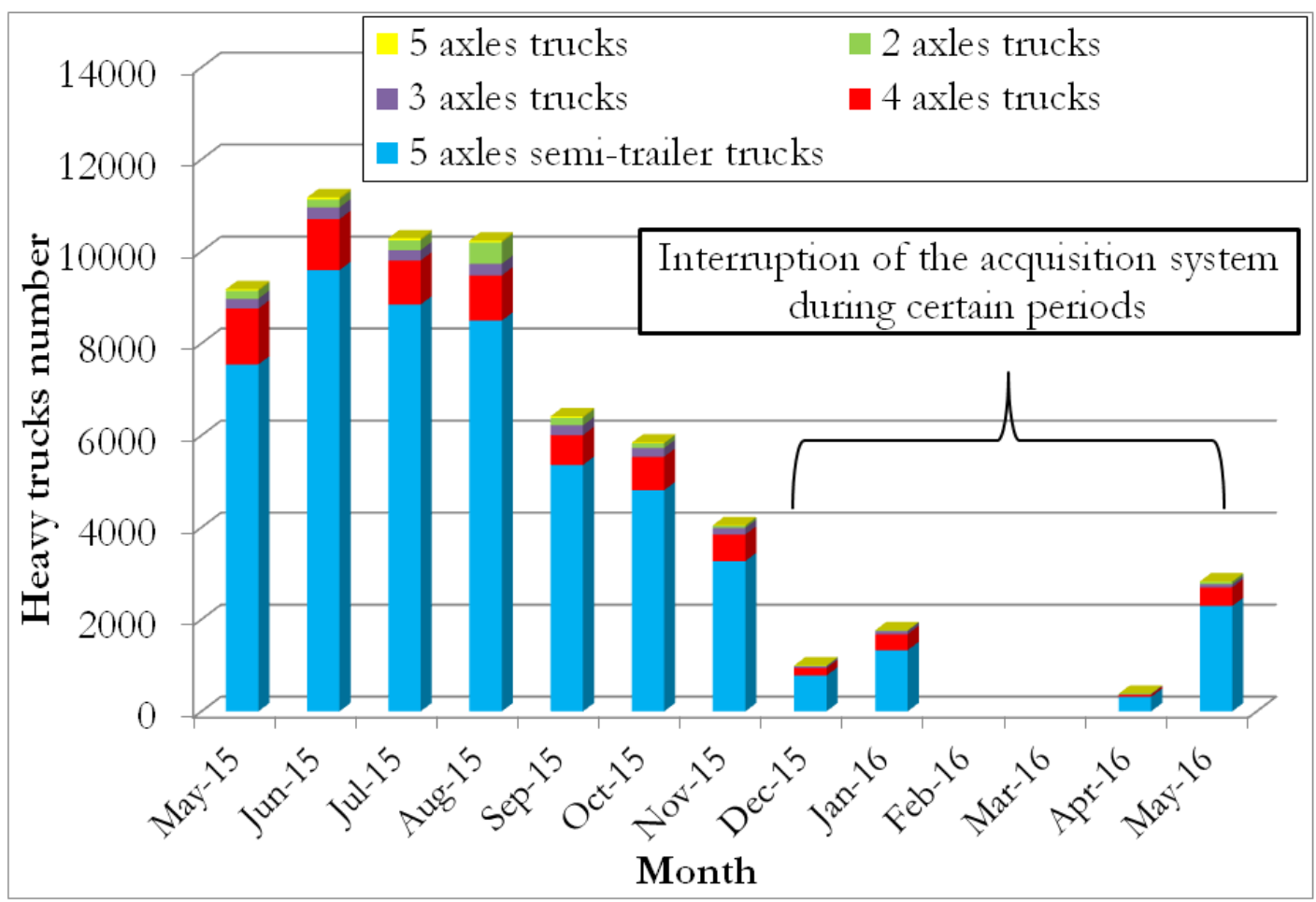

Figure 9. Distribution of different heavy vehicle types on the motorway

\subsection{Calculation of heavy vehicle speeds}

Two geophones G1 and G2 have been placed at the bottom of the HMAC layer, at a distance of 1 meter of each other, in the longitudinal direction. Their results have 
been used to calculate heavy vehicle speeds, using the time difference between the signals of the two geophones. The speed $\mathrm{v}$ of a vehicle is given by the formula

$$
v=\frac{d}{t}
$$

where : $d$ is the distance between the two geophones $(1 \mathrm{~m})$

$t$ is the time interval between the responses of two geophones. This time interval has been defined as the time difference between the first negative peak of each signal, as illustrated in figure 10.

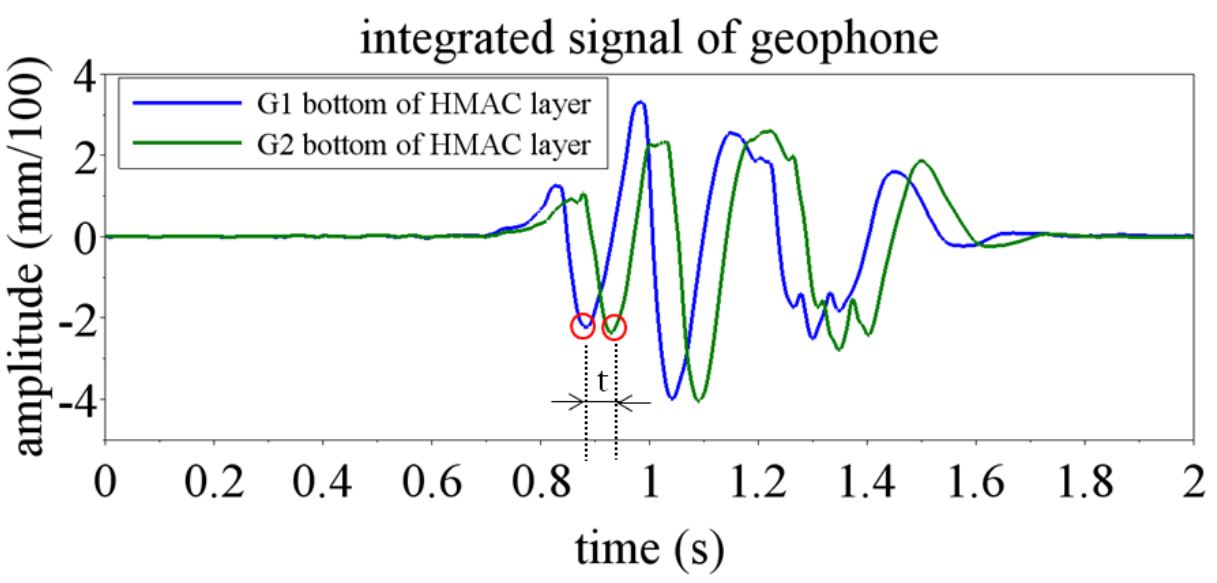

Figure 10. Time difference between two geophones signals

Figure 11 presents the monthly average values of heavy vehicle speeds calculated for the motorway section using this method. It can be noted that the speeds remain relatively constant during the monitoring period. The average speeds of heavy vehicles vary between 76 and $80 \mathrm{~km} / \mathrm{h}$, which is consistent with the speed limit of 90 $\mathrm{km} / \mathrm{h}$, that applies for heavy vehicles on French motorways. 


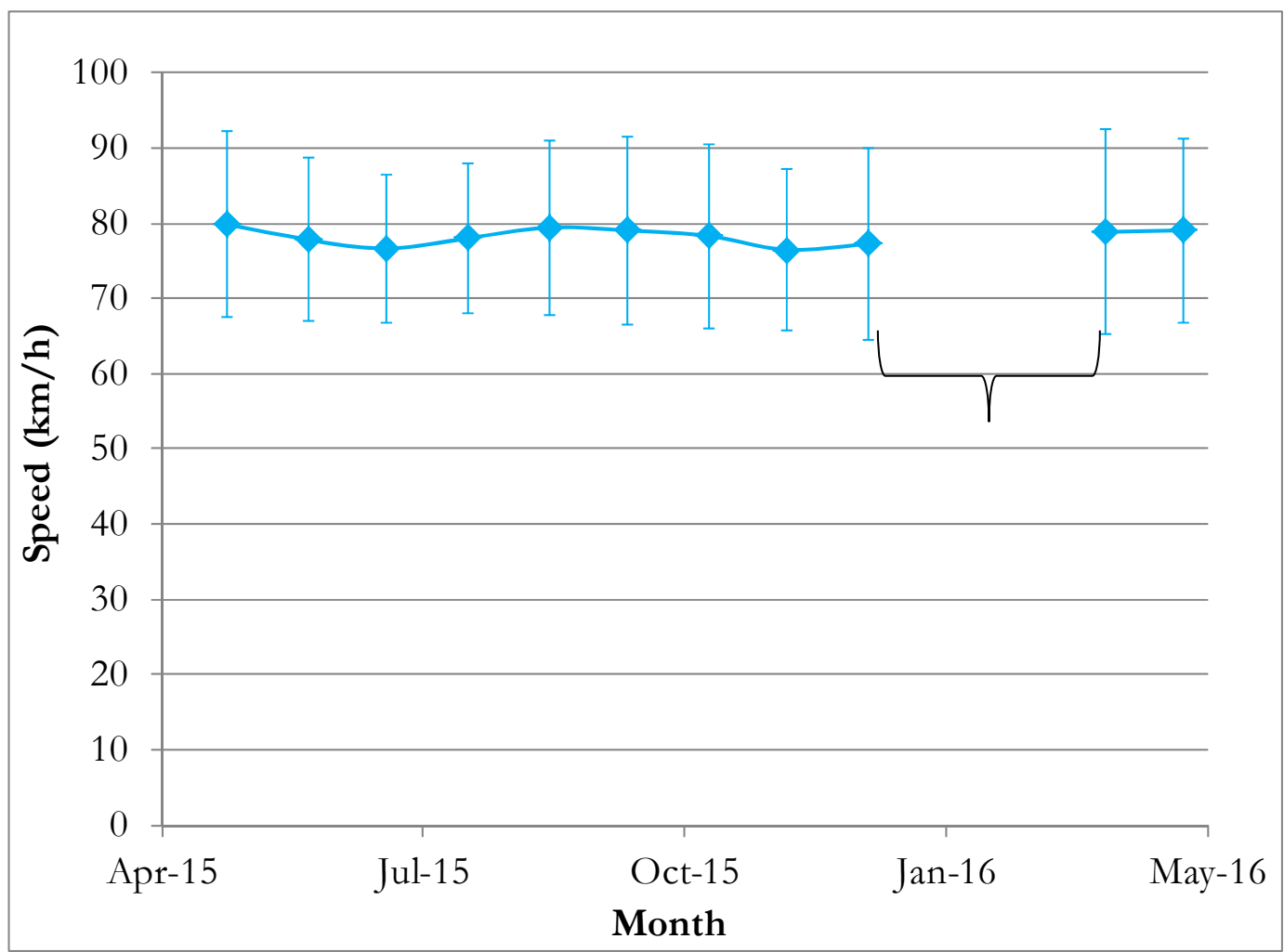

Figure 11. Monthly average values of heavy vehicle speeds on the motorway

\section{Estimation of pavement deflections}

\subsection{Procedure for correction of the geophone signals}

As discussed in section 4.1, the geophones installed in the pavement measure locally the vertical displacement velocity. Then, the corresponding displacement can be obtained by integrating the raw signal of the geophone. However, this operation gives unrealistic information since the resulting signal indicates several large upward displacements ("uplift") of the pavement (Figure 7). In comparison, deflection measurements made on the pavement surface with certified measurement devices (deflectograph, FWD, Benkelman beam or curviameter) clearly indicate a negative displacement ("downward") under the vehicle load. Similarly, calculations with linear elastic or viscoelastic pavement models indicate essentially a downward displacement 
(a very small upward movement may be observed, but it is of a much smaller magnitude)We have identified mainly two reasons which may explain the distortion of the displacement signal:

- The frequency response of the geophones used in the experiments causes an amplification of several parts of the signal while others are attenuated (especially the low frequencies).

- The vibration recorded by the geophone corresponds to a non-zero average signal. So, as a constant appears during the numerical integration, the shape of the final signal can be distorted.

In order to obtain a deflection signal with more realistic features, the following methodology is proposed (Figure 12) : The first step consists in decomposing the raw signal into a low-frequency component and a high-frequency component. The value of the cut-off frequency ( $\mathrm{fc}=4.5 \mathrm{~Hz}$ ) of the filter used for the decomposition has been selected according to the transfer function of the geophone. The low-frequency component, which is linked to the total duration of the vehicle loading ( 1 second for a vehicle length of about $20 \mathrm{~m}$, at $20 \mathrm{~m} / \mathrm{s}$ ), is then amplified in order to offset the intrinsic attenuation of the sensor and to increase the amplitude of the signal in this frequency interval.

The next step consists in calculating the displacement corresponding to each component by a numerical integration. A detrending operation is then applied to remove the continuous constant due to the integration.

For removing the oscillations of the displacement signal, a Hilbert transform has been applied to both components. The Hilbert transform is commonly used in 
demodulation operations for extracting an initial information signal from a carrier wave (e.g. sine wave signal) (Claerbout, 1985). As the oscillations observed in the geophone signals recall those of a modulated signal, the Hilbert transform has been tested in this study.

The Hilbert transform of a signal $\mathrm{x}(\mathrm{t})$ is defined as the transform in which the phase angle of all components of the signal is shifted by \pm 90 degrees. In this way, the application of the Hilbert transform to a sine signal gives a cosine signal with the same magnitude. So, in case of a demodulation operation, when a signal is combined with its Hilbert transform, the oscillations corresponding to the carrier wave can be removed and the "envelope" of the signal can be extracted.

Let $\hat{x}(t)$ be the Hilbert transform $H$ of the signal $(t)$ :

$$
\begin{gathered}
\widehat{x}(t)=H\{x(t) \\
\widehat{x}(t)=H\{x(t)\}=\int_{-\infty}^{+\infty} \frac{1}{\pi} \times \frac{x(\tau)}{(t-\tau)} d \tau=(h * x)(t)
\end{gathered}
$$

Where $h(t)=\frac{1}{\pi t}$

In the frequency domain, the spectrum of the Hilbert transform is obtained with the Fourier transform (FT). This expression clearly shows the shift of the phase angle of the signal related to the Hilbert transform.

$$
\boldsymbol{F T}\{\widehat{x}(\boldsymbol{t})\}=X(\omega)[-j \times \operatorname{sgn}(\omega)]
$$

Where $X(\omega)=F T\{x(t)\}$ and $\operatorname{sgn}(\omega)$ is the sign function applied to the frequency $\omega$.

The principle of the signal correction, based on the use of the Hilbert transform, for extracting the envelope of the signal is described below. This operation requires the 
use of an analytical signal which is coming from the combination of the signal to process and its Hilbert transform.

Let $s_{A}(t)$ be the analytical signal composed of a signal $s(t)$ as the real part and its Hilbert transform $\hat{s}(t)$ as the imaginary part :

$$
s_{A}(t)=s(t)+j \hat{s}(t)
$$

The corrected signal retained at the end of the process, $e(t)$, corresponds to the envelope of the signal $s_{A}(t)$, given by :

$$
e(t)=\sqrt{\left\{\operatorname{Re}\left(s_{A}(t)\right\}^{2}+\left\{\operatorname{Im}\left(s_{A}(t)\right\}^{2}\right.\right.}=\sqrt{s^{2}(t)+\hat{s}^{2}(t)}=\left|s_{A}(t)\right|
$$


Step 0. Initial signal

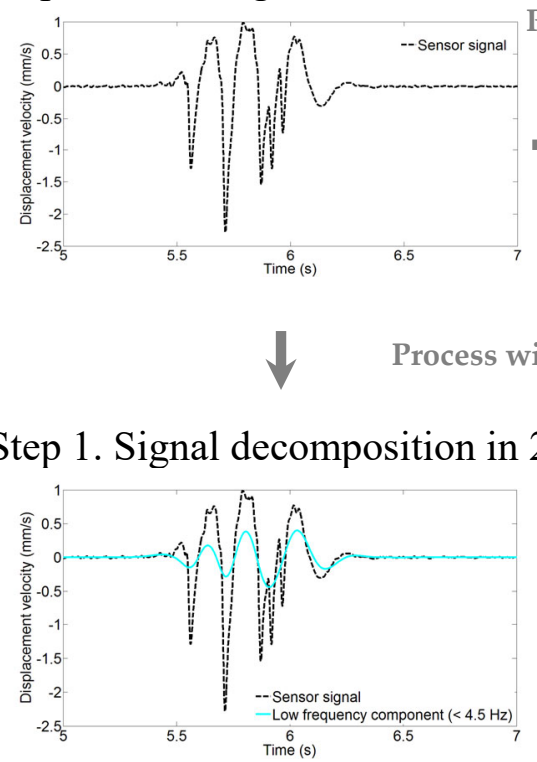

Step1. Numerical integration

rocess without

signal

correction

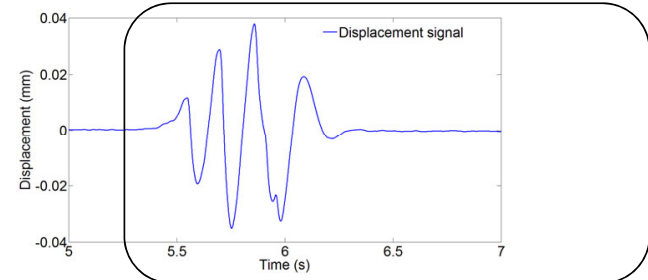

Step 2. Low-frequency amplification

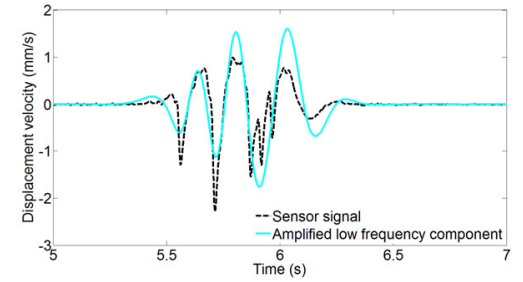

Step 3. Numerical integration
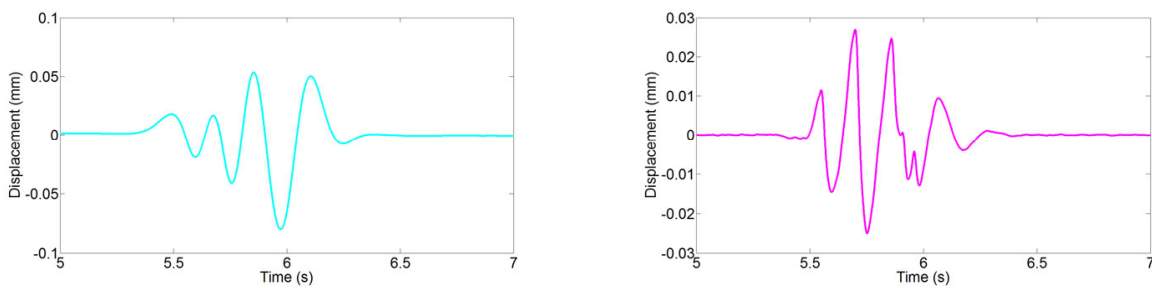

Step 4 . Signal correction using the Hilbert transform
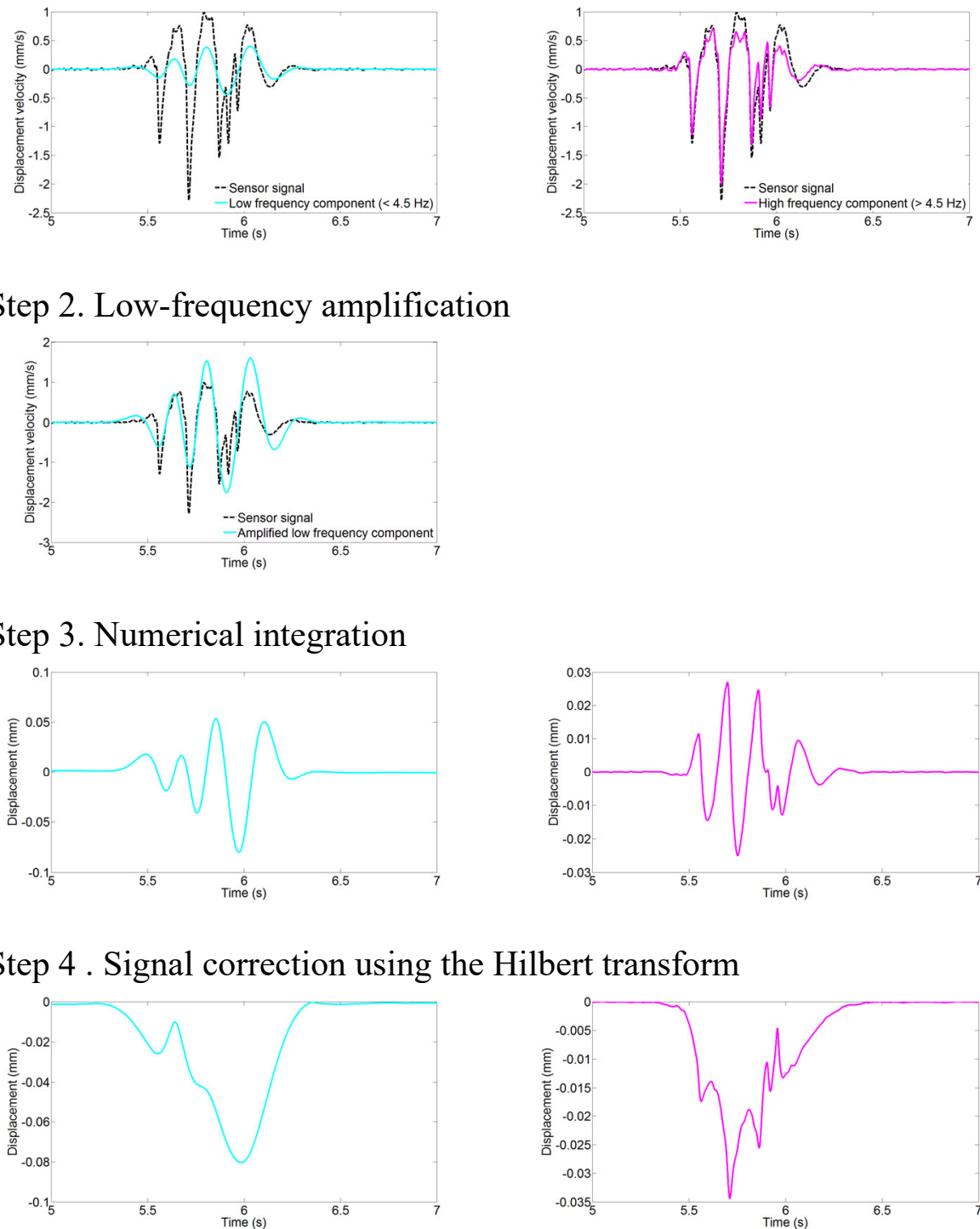


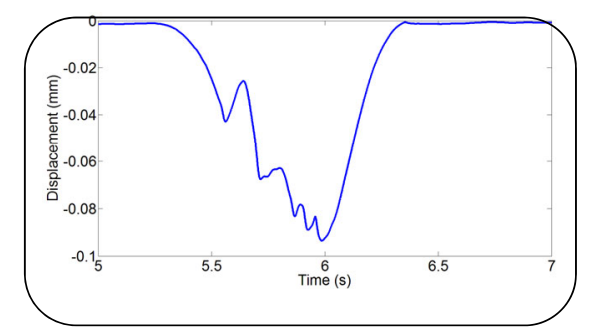

Figure 12. Illustration of the geophone signal correction process

The proposed signal correction process has been applied to several experimental signals, to test its effect on the global shape of the deflection signal, and on its amplitude. An example of correction is illustrated in figure 13. The geophone signal has been recorded under the passage of a 5-axle semi-trailer truck (loaded at 44 tons) at 15h31 on March 18th 2014. The truck used was weighted before measurements. The results show that :

- After correction, the shape of the displacement signal is much more realistic, and the upward displacement is eliminated. The signal presents five peaks, corresponding to the passage of the five axles of the heavy vehicle.

- The maximum deflection value is about $5.5 \mathrm{~mm} / 100$. This value is of the same order of magnitude as the deflection measured on the pavement with an FWD, under a $65 \mathrm{kN}$ load. 

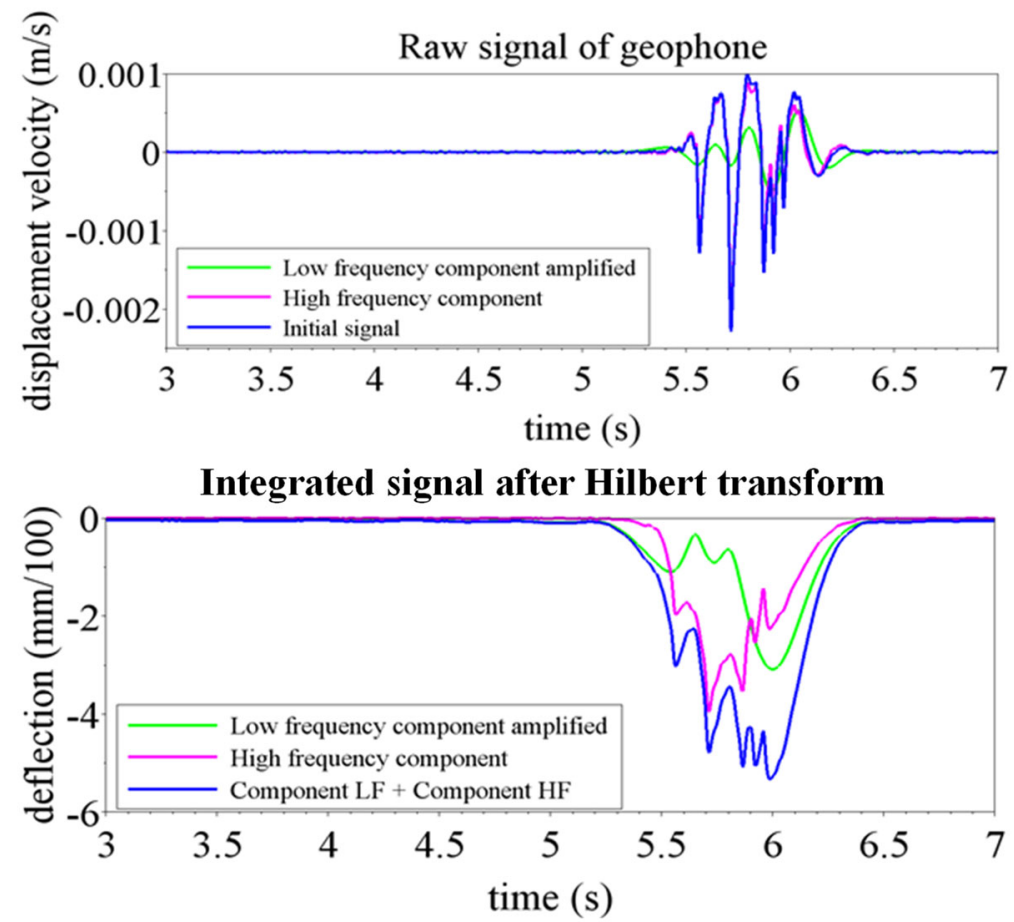

Figure 13. Deflection obtained by the correction method, with amplification of the lowfrequency component of a signal recorded at 15h31min on March 18th 2014 under a 5axles semi-trailer truck (loaded at 44 tons)

The results are encouraging: the correction procedure seems to reproduce correctly both the shape and the amplitude of the pavement deflection. To validate this procedure, tests have been performed on the IFSTTAR accelerated pavement testing facility, under controlled wheel loading. The objective of these tests was to adjust different parameters of the method (cut-off frequency, amplification coefficient of the low-frequency component), and to validate the deflections obtained with the geophones, by comparison with measurements made with a reference displacement transducer.

\subsection{Validation of the correction method by tests on the IFSTTAR accelerated} pavement testing facility 
The IFSTTAR accelerated pavement testing facility (APT), in Nantes, is an outdoor circular test track (or carousel), dedicated to full-scale pavement experiments, carried out with public and/or private partners [1]. The carousel consists of a central tower and four arms (each $20 \mathrm{~m}$ long) equipped with wheels, running on a circular test track (Figure 14). The experimental pavement has a mean radius of $17.5 \mathrm{~m}$ and a width of $6 \mathrm{~m}$, and thus a total length of approximately $110 \mathrm{~m}$. The loading modules can be set at different lateral positions on each arm, for instance to test simultaneously the effect of different load configurations. During loading, a lateral wandering of the loads can be applied to simulate the lateral distribution of loads of real traffic (Gramsammer et al., 1999 and Autret et al., 1997).

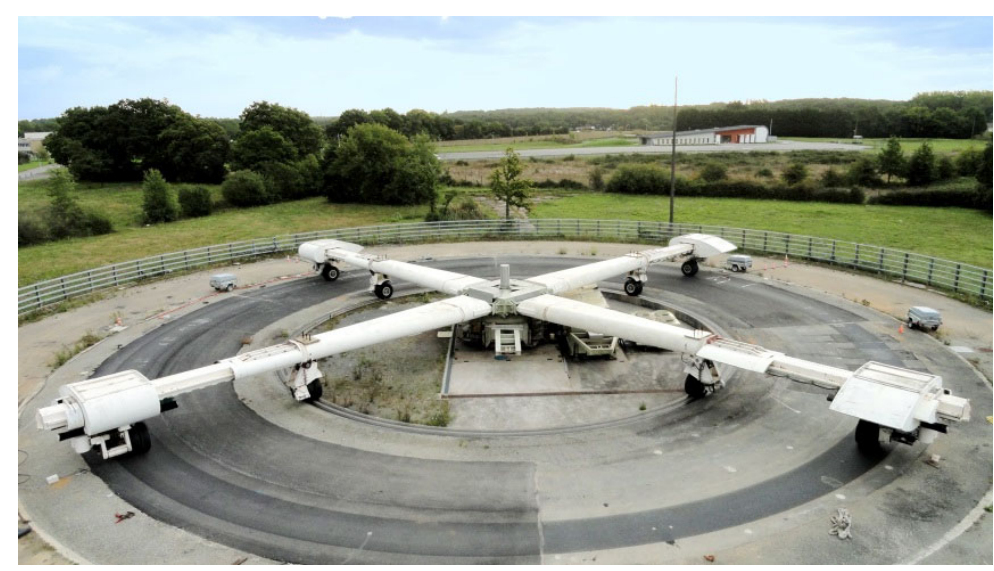

Figure 14. IFSTTAR accelerated pavement testing facility

The pavement structure used for the tests is presented in table 3 . It is a flexible pavement which supports a low traffic.

Table 3. Pavement structure tested on the IFSTTAR accelerated pavement testing facility

\begin{tabular}{cc}
\hline Materials & Thickness (cm) \\
\hline 0/10 mm asphalt concrete & 10 \\
Unbound granular material & 30 \\
Soil & - \\
\hline
\end{tabular}


For the evaluation of the geophone measurements, two geophones and one anchored displacement sensor were embedded in the asphalt concrete layer. The anchored displacement sensor consists of an Linear Variable Differential Transformer (LVDT), which measures the vertical displacement (or deflection) between the top of the bituminous layer and a reference point anchored at 4 meters depth. The anchored sensor is used as a reference measurement, to measure the deflection of the pavement. The instrumentation layout is presented in figure 15. The dual wheels used on the carousel are loaded at $65 \mathrm{kN}(32.5 \mathrm{kN}$ on each wheel).

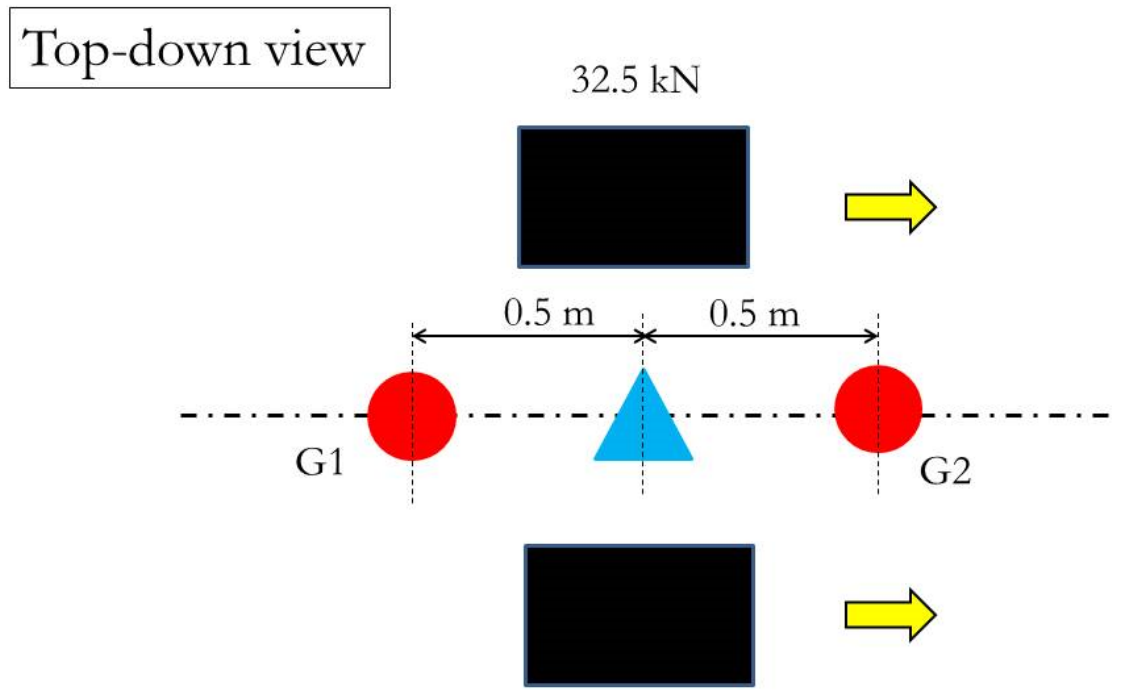

$32.5 \mathrm{kN}$

Geophone

Anchored sensor

Figure 15. Top-down view indicating the position of the geophones and of the anchored sensor, compared to the position of the wheels of the IFSTTAR accelerated pavement testing facility

For the tests, two series of measurements were performed: 
- A first series of measurements were performed on March 14th 2017, at different speeds, varying from $6 \mathrm{~m} / \mathrm{s}$ to $20 \mathrm{~m} / \mathrm{s}$, and at a constant temperature.

- A second series of measurements were performed on March 15th 2017. The measurements were performed at different times of the day $(9 \mathrm{~h} 42,11 \mathrm{~h} 54$ and 15h36), corresponding to different temperatures, and at a constant speed of $10 \mathrm{~m} / \mathrm{s}$.

The purpose of the tests was to validate the measurements of the geophones, and to adjust the parameters of the correction method, to match the deflections measured by the anchored sensor. The parameters are:

- The frequency used for the filtering of the geophone signal.

- The amplification coefficient of the low frequency component.

The filtering frequency is related with the cut-off frequency of the geophone, which is about $4.5 \mathrm{~Hz}$. For this reason, it was decided to test five different filtering frequencies: $3 \mathrm{~Hz}, 3.5 \mathrm{~Hz}, 4 \mathrm{~Hz}, 4.5 \mathrm{~Hz}$, and $5 \mathrm{~Hz}$. For each frequency, the amplification coefficient of the low frequency signal component has been adjusted to match the displacement amplitude measured by the anchored sensor. An example of comparison between the deflections measured by the two geophones and by the anchored displacement sensor is presented in figure 16. In this example, the filter frequency selected is $4.5 \mathrm{~Hz}$, and the amplification coefficient obtained is 1.4.

As shown on figure 16, after applying the correction method, the maximum deflection predicted using the geophones is very close to the reference value measured by the anchored displacement sensor. The two geophones also give very similar values, indicating the good repeatability of the measurements. However, the shape of the 
signals is somewhat different. The duration of the geophone signal is greater than that of the displacement transducer signal. The geophone seems to react earlier to the approaching load than the displacement sensor. However, the difference in shape of the signals is not critical, as the main objective is to predict the maximum deflection.

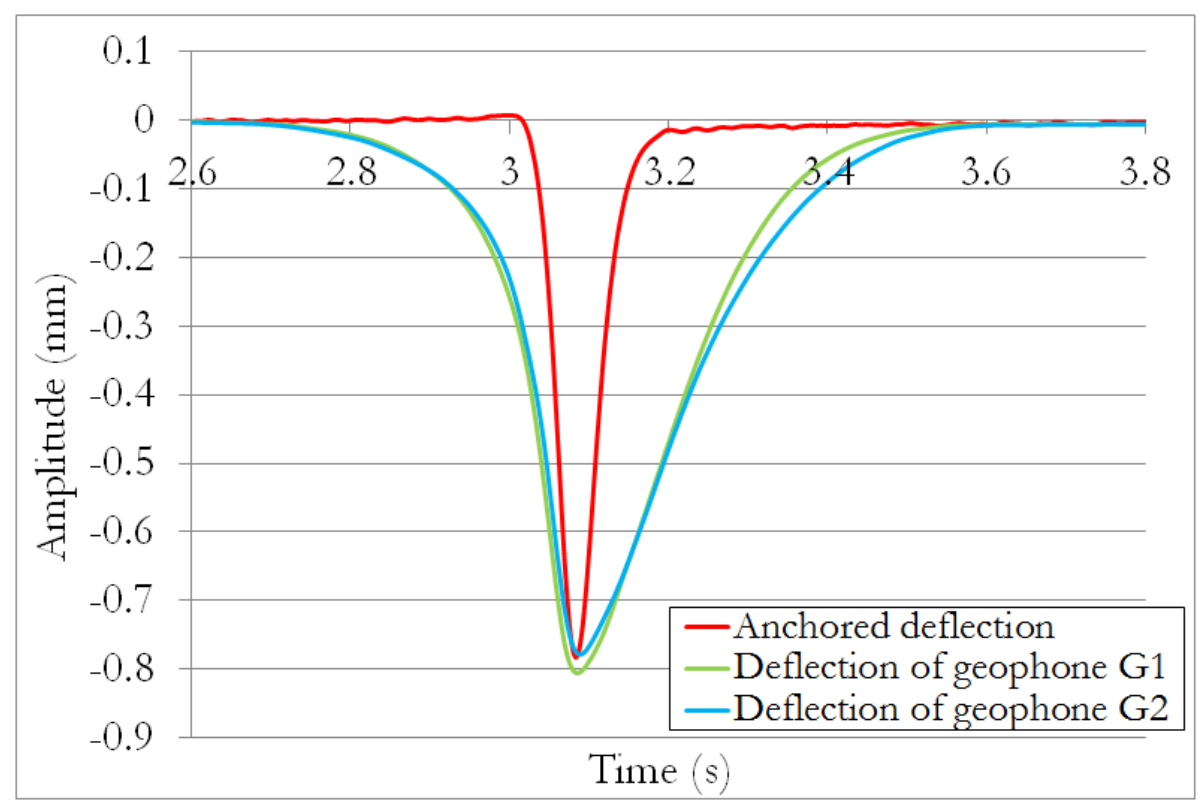

Figure 16. Example of comparison of the corrected geophone measurements with the signal of the anchored sensor. Measurement at 9h42 on March 15th 2017 (cut-off frequency $=4.5 \mathrm{~Hz}$; amplification coefficient $=1.4$ )

Then, the correction method has been applied to the analysis of the two series of measurements. Figure 17 presents the variation of the amplification coefficients obtained for different filter frequencies (from $3 \mathrm{~Hz}$ to $5 \mathrm{~Hz}$ ), for the series of tests at different speeds and constant temperature. Each value corresponds to the average of the coefficients obtained for the two geophones. Their values were generally very close. The results indicate that at constant speed, the amplification coefficient decreases when the filter frequency increases. The amplification coefficient also decreases when the speed increases. At a speed of $20 \mathrm{~m} / \mathrm{s}(72 \mathrm{~km} / \mathrm{h})$, which is close to the speed of heavy 
trucks on the motorway, the amplification coefficient tends toward values close to $1:$ it varies between 1.1 for a filter frequency of $3 \mathrm{~Hz}$, and 1 , for a filter frequency of $5 \mathrm{~Hz}$.

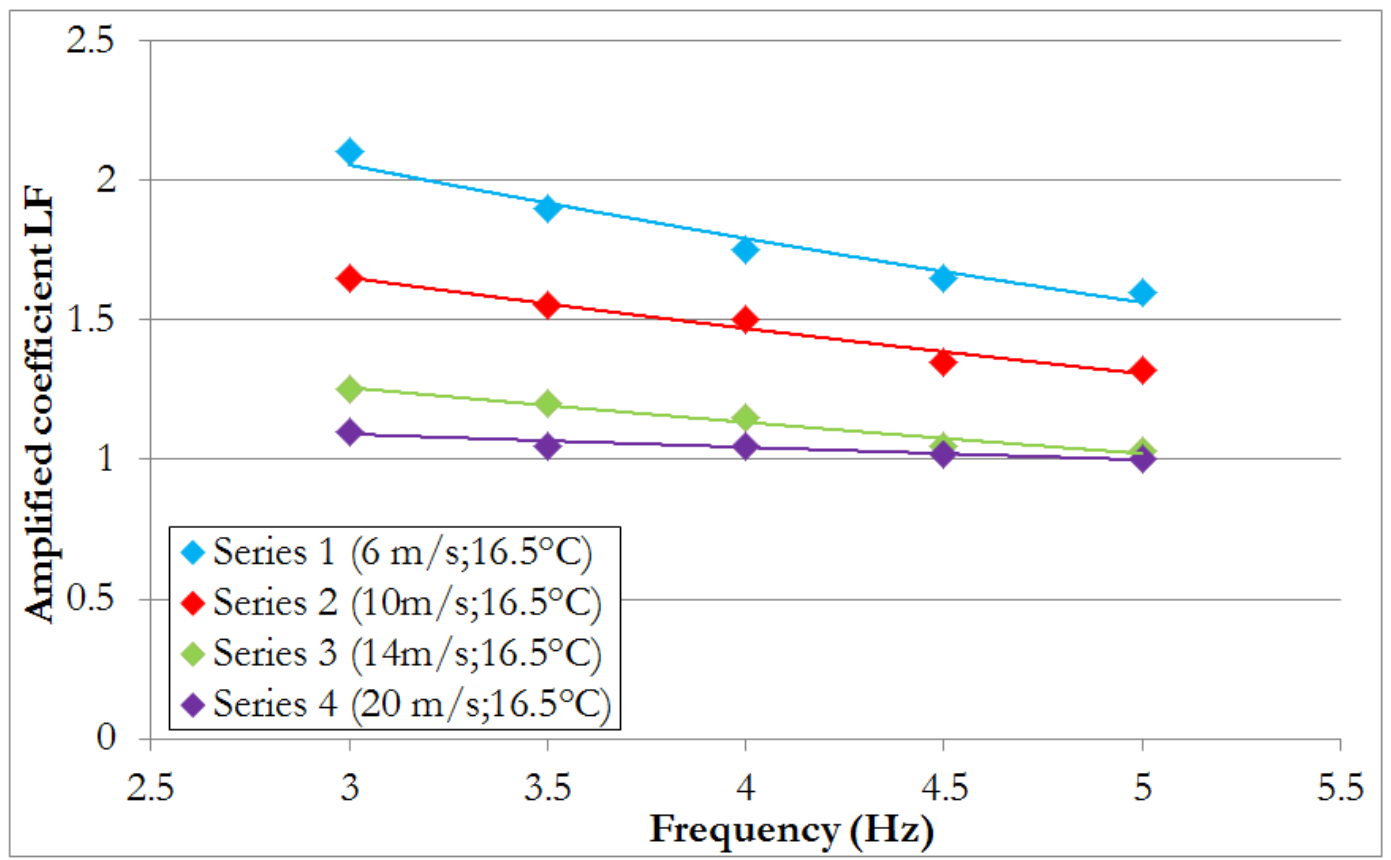

Figure 17. Application of the correction method for different filter frequencies (from 3 to $5 \mathrm{~Hz}$ ). Variation of the amplification coefficient obtained, for different loading speeds

Table 4 presents the values of the coefficients of amplification of the low frequencies obtained, with the correction method, for a filter frequency of $3 \mathrm{~Hz}$ and for different speeds (from $6 \mathrm{~m} / \mathrm{s}$ to $20 \mathrm{~m} / \mathrm{s}$ ) at a temperature of $16.5^{\circ} \mathrm{C}$. The amplification coefficient decreases from 2.1 to 1.1 when the loading speed increases from $6 \mathrm{~m} / \mathrm{s}$ to $20 \mathrm{~m} / \mathrm{s}$. This result indicates that the amplification of the low frequency components becomes less and less necessary as the loading speed increases. In addition, the results obtained with the second measurement series, at constant speed, have shown that the coefficient of amplification remains nearly unchanged at different temperatures, when the selected filter frequency is $3 \mathrm{~Hz}$ (with temperatures between 13 and $20^{\circ} \mathrm{C}$ ). Therefore, for the correction of the geophone measurements it has been decided to retain the filter 
frequency of $3 \mathrm{~Hz}$, which seems to minimize the influence of temperature on the correction coefficients.

Table 4. Values of the coefficient of amplification of low-frequencies obtained for different loading speeds, and for a constant temperature of $16.5^{\circ} \mathrm{C}$ (filter frequency $=$ $3 \mathrm{~Hz})$

\begin{tabular}{cc}
\hline Cut-off frequency $=\mathbf{3 ~ H z}$, temperature $=\mathbf{1 6 . 5}^{\circ} \mathbf{C}$ \\
\hline LF Amplification coefficient & Speed $(\mathbf{m} / \mathbf{s})$ \\
2.1 & 6 \\
1.65 & 10 \\
1.25 & 14 \\
1.1 & 20 \\
\hline
\end{tabular}

\subsection{Application of the correction method for pavement monitoring}

The method of correction of the geophone measurements has been validated using tests on the IFSTTAR accelerated pavement testing facility. The results of the tests have indicated that with the proposed correction method, it is possible to predict correctly the deflection amplitudes, provided that a correction coefficient, depending on the loading conditions, is introduced, to correct the amplitude of the low frequency components of the signal. It has also been shown that :

- The amplification coefficient decreases when the loading speed increases.

- The amplification coefficient is less dependent on temperature variations when a filter frequency of $3 \mathrm{~Hz}$ is used.

This original correction procedure has been applied to the processing of the geophone measurements, on the instrumented motorway section. To evaluate the effect of the procedure, the corrected geophone signals have been compared with calculations with the French pavement design software ALIZE-LCPC [2]. This software is based on the multi-layer linear elastic model of Burmister (Burmister, 1943) in compliance with 
the French pavement design guide (LCPC-SETRA, 1994 and Corte and Goux, 1996). The pavement layers are assumed to be homogeneous, isotropic and infinite in the horizontal plane.

For these comparisons, signals recorded under the passage of a 5-axles semitrailer truck (with a total weight of 44 tons) at about $80 \mathrm{~km} / \mathrm{h}$ have been used. The pavement structure (see table 1), and the semi-trailer loads have been simulated with ALIZE-LCPC, and the calculated deflections have been compared with the geophone measurements.

Figure 18 presents an example of comparison of corrected geophone signal, and calculated deflection, under the five axle semi-trailer, at $15^{\circ} \mathrm{C}$ and $10 \mathrm{~Hz}$. According to the previous calibration, a filter frequency of $3 \mathrm{~Hz}$, and a coefficient of amplification of low frequencies of 1.1 has been used. The result shows that:

- The maximum displacement amplitude calculated with ALIZE-LCPC is about $5.5 \mathrm{~mm} / 100$.

- The corrected geophone signal presents five peaks, corresponding to the five axles of the heavy truck. The maximum deflection (about $5.5 \mathrm{~mm} / 100$ ), is of the same order of magnitude as the calculated values. However, the shape of the signal is not very satisfactory, and could still be improved. The correction process introduces a time distortion, and reduces the signal variation between the peaks corresponding to the successive axles. Results could probably be improved by using a geophone with a lower natural frequency, which would lead to a less important attenuation of the signal at low frequencies (for the geophone GS-11D, this natural frequency is $4.5 \mathrm{~Hz}$ ). Further research is planned to test other types of geophones. 


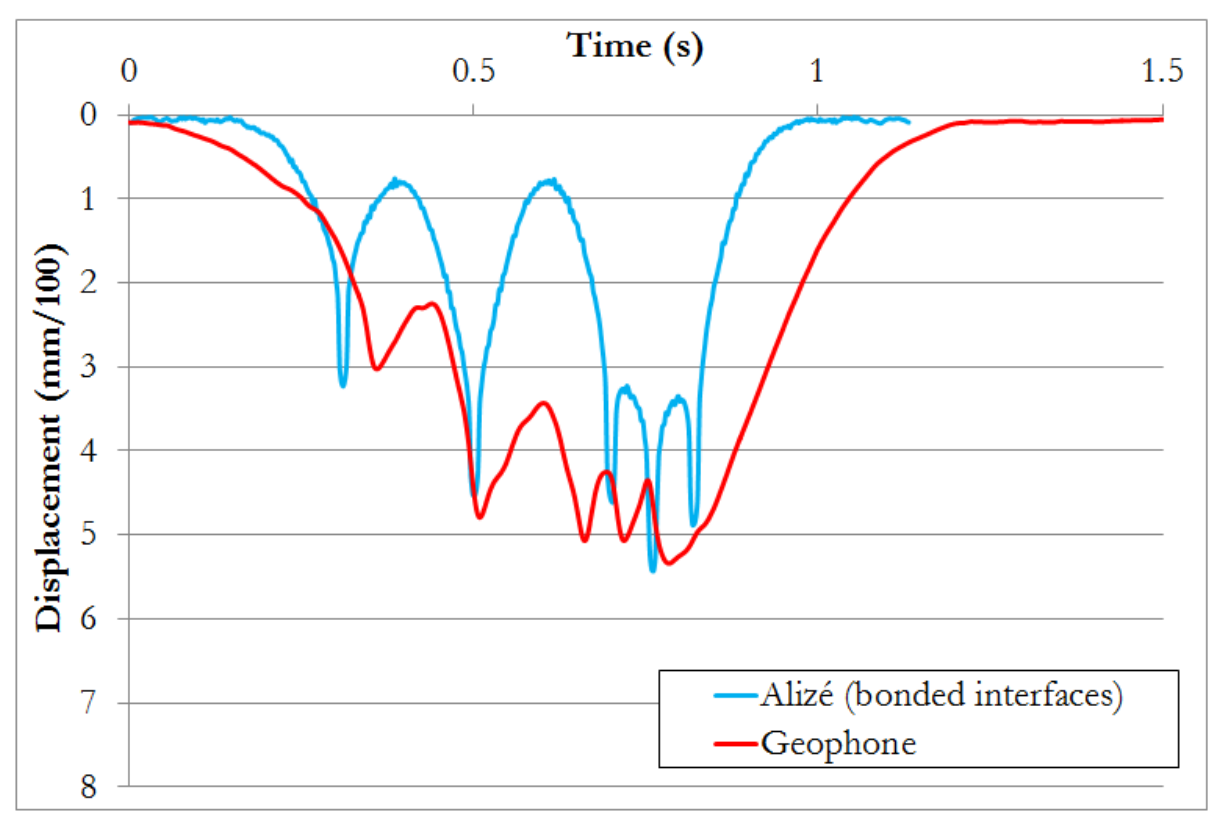

Figure 18. Comparison of deflection calculated under a 5-axle semi-trailer, and corrected geophone signal. ALIZE-LCPC calculation at $15^{\circ} \mathrm{C}$ and $10 \mathrm{~Hz}$

Finally, the correction process has been used to analyse the deflections recorded on the motorway section, under traffic, for a period of over one year. The signals used for this study were selected : only the five axles semi-trailers passing in the middle of the wheel path were used. So the wandering was not studied here.

A temperature correction adjustment was applied to the deflection. The equation given in the French technical guide on pavement reinforcement (CEREMA-IDDRIM, 2016) was used (eq. 8).

$$
d_{15^{\circ} \mathrm{C}}=\frac{d_{\theta m e s}}{1+K *\left(\theta_{\text {mes }}-15\right) / 15}
$$

With :

- $\mathrm{d}_{15^{\circ} \mathrm{C}}$ : deflection at $15^{\circ} \mathrm{C}$ (reference temperature in France)

- $\mathrm{d}_{\theta \mathrm{mes}}$ : deflection at the temperature of measurement $\theta$ mes 
- $\mathrm{K}$ : constant depending of the type of the pavement, here $\mathrm{K}$ is equal to 0.08

Figure 19 presents the evolution of the monthly average maximum values of deflection, with and without temperature correction and the mean temperature at the bottom of the HMAC layer. The influence of the temperature is small, probably because the pavement has a cement treated sand subbase, which is not affected by temperature variations.

The results show that the mean deflections are relatively stable during the year, indicating no significant seasonal variations of the bearing capacity of the pavement, and no pavement deterioration during the monitoring period.

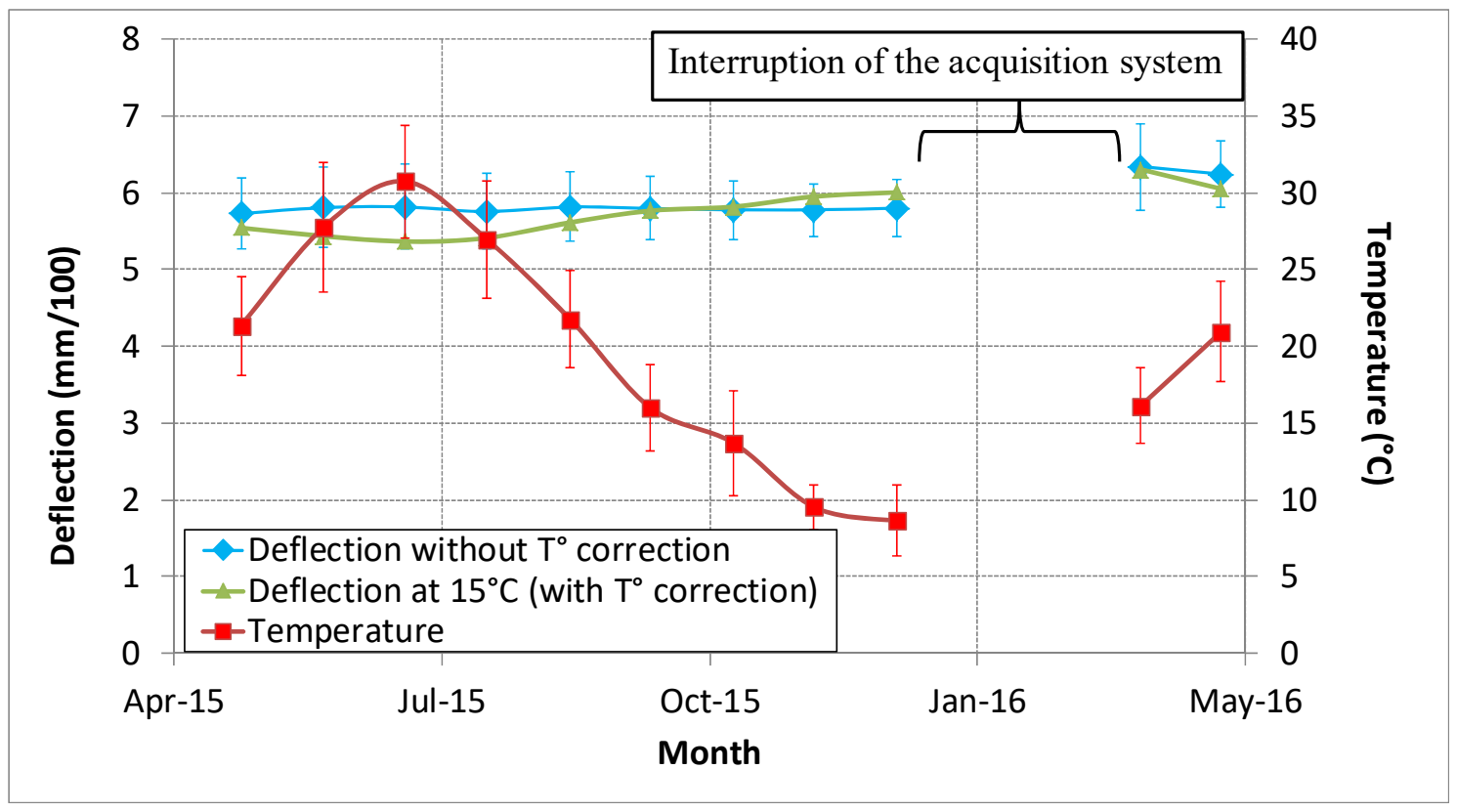

Figure 19. Evolution of monthly average maximum values of deflection (with and without temperature correction) on the motorway section and mean temperature at the bottom of the HMAC 


\section{Conclusion}

Geophones are sensors developed for the measurement of displacement velocities. They are used in various applications, such as detection of ground motions, for seismic applications. In this project, different applications of geophone measurements for the instrumentation of a motorway section, with continuous monitoring of the measurements under normal traffic, have been tested.

The geophones have been installed in the bituminous base layer of the pavement, at several lateral and longitudinal positions, under the wheel path of the passing vehicles. The first results have shown that the geophone measurements are very sensitive to the small displacement levels produced by the traffic on the motorway. Two main applications of these sensors have therefore been evaluated :

- The counting of heavy vehicle traffic, and the identification of the different heavy vehicle silhouettes;

- The measurement of pavement deflections, and the monitoring of their evolution, under the effects of traffic and climatic conditions

The procedure for counting and identification of truck silhouettes consists first in defining a measurement threshold, which must be exceeded, to trigger the acquisition of the geophone signal. The adjustment of this threshold allows to record only heavy vehicle traffic. Then, after integration of the geophone signal, to obtain a displacement, a simple procedure of identification of the signal peaks can be used to identify and count the different types of heavy vehicle silhouettes, passing on the instrumented lane. This procedure can be used to detect truck silhouettes with a good accuracy (95\%), and examples of distribution of different truck silhouettes obtained on the instrumented section have been presented. In addition, a procedure for measuring heavy vehicle 
speeds, based on the use of two geophones, separated by a distance of $1 \mathrm{~m}$, in the longitudinal direction, has also been tested.

For the measurement of pavement deflections, it has been shown that a simple integration of the geophone signals is not sufficient to obtain accurate deflection values. A specific procedure, for the correction of the geophone signals, based on the application of the Hilbert Transform, and on the amplification of the low frequency components of the signals, has been developed. The amplification coefficient depends on vehicle speed, and a calibration is necessary, to determine its values, for different speed levels. This procedure has been evaluated, by comparison with deflection measurements made on the IFSTTAR accelerated pavement testing facility, and with modelling results. Encouraging results, indicating good predictions of maximum deflections, have been obtained. However, the shape of the corrected deflection signals is not completely realistic, and could still be improved.

This study has clearly shown the potential of geophones for pavement monitoring. A first procedure, for correcting the geophone signals has been proposed, but further research is planned, to test different types of geophones, with different frequency response characteristics, to try to obtain more accurate deflection signals.

\section{References}

Al Hakim B., Cheung L.W. and Armitage R.J., 2007. Use of FWD data for prediction of bonding between pavement layers, International Journal of Pavement Engineering, 1(1).

Autret P., de Boissoudy A.B., Gramsammer J.C., 1997. The circular test track of the Laboratoire Central des Ponts et Chaussées - First Results. Proceeding of the 6th International Conference on Structural Design of Asphalt Pavements, Ann Arbor, USA, Vol. 1, 550-561. 
Blanc, J., Hornych, P., Duong, N.S, Blanchard, J.Y., Nicollet, P., 2017. Monitoring of an experimental motorway section. International Journal of Road Materials and Pavement Design, Published online, http://dx.doi.org/10.1080/14680629.2017.1374997.

Burmister, D. The theory of stress and displacements in layered systems and applications of the design of airport runways, 1997. Proceedings of the Highway Research Board, Volume 23.

CEREMA-IDRRIM，2016. Guide technique - Diagnostic et conception des renforcements de chaussées [Technical guide, in French]

Claerbout, J.F.,1985. Fundamentals of Geophysical Data, Processing with Applications to Petroleum Prospecting. Oxford, UK: Blackwell.

Corte J.F. and Goux M.T., 1996. Design of Pavement Structures : The French Technical Guide, Transportation Research Record, Vol 1539, 116-124.

Duong, N.S.; Blanc, J.; Hornych, P., 2017. Analysis of the behavior of pavement layers interfaces from in-situ measurements. Tenth International Conference on the Bearing Capacity of Roads, Railways and Airfield, Athens, Greece.

Duong, N.S; Blanc, J.; Hornych, P., 2018. Continuous strain monitoring of an instrumented pavement section. International Journal of Pavement Engineering," published online, https://doi.org/10.1080/10298436.2018.1432859

Duong, N.S., Blanc, J., Hornych, P., 2016. Instrumentation of an innovative pavement section on motorway A10. Advances in Pavement Design through Full-scale Accelerated Pavement Testing, Costa-Rica.

FHWA, 2016. Pavement structural Evaluation at the Network Level : Final Report, Report $n^{\circ}$ FHWA-HRT-15-074, September 
Gramsammer J.C., Kerzrého J.P., Odéon H., 1999. The LCPC's A.P.T. Facility: Evaluation of fifteen years of experimentation, International Conference of Accelerated Pavement Testing, Reno, Nevada, October.

Katicha S.W., Flintsch G.W., Ferne B., Bryce J., 2013. Limits of agreement method for comparing TSD and FWD measurements, International Journal of Pavement Engineering, 15(6).

LCPC-SETRA., 1994. Conception de dimensionnement des structures de chaussées: Guide technique national, France,.

Le Cam, V., Cottineau, L-M., Lemarchand, L., Bourquin, F., 2008. Design of a generic smart and wireless sensors network - Benefits of emerging technologies. Structural Health Monitoring.

Lenglet C., Blanc J., Dubroca S., 2017. A smart road that warms its network manager when it begins cracking, IET Intelligent Transport Systems, April,11(3), 152157. 10.1049 /iet-its. 2016.0044

Oome, A. et al., 2009. Modeling of an electromagnetic geophone with passive magnetic spring. Sensors and Actuators A: Physical, 142-154.

Sohm, J.; Hornych, P.; Kerzrého, J-P.; Cottineau, L-M.; Le Cam, V.; Hautière, N; De la Roche, C.; Van Damme, H., 2012. Remote Monitoring of An Experimental Motorway Section. International Journal of Pavement Research and Technology, Issue 5, 289-294.

(1) http://www.lames.ifsttar.fr/en/theinstitute/mast/laboratories/lames/equipments/the-pavement-fatigue-carrousel/

(2) http://www.alize-lcpc.com/index.php 